\title{
RADIOCARBON DATING REPRODUCIBILITY AT THE MUSEO DE LA PLATA RADIOCARBON LABORATORY
}

\author{
ANIBAL FIGINI, ROBERTO HUARTE AND JORGE CARBONARI
}

\author{
Laboratorio de Tritio y Radiocarbono, LATYR \\ Facultad de Ciencias Naturales y Museo, Paseo del Bosque, 1900 La Plata, Argentina
}

\begin{abstract}
We discuss here the variability, for our laboratory, in counting for radiocarbon dating of replicate measurements of background and secondary modern standard, duplicate measurements of samples provided by the International Collaborative Study, and replicate measurements of the dilution of the ${ }^{14} \mathrm{C}$-labeled benzene standard. The variability in the measurements of the International Collaborative Study samples suggest the existence of systematic bias.
\end{abstract}

\section{INTRODUCTION}

The error commonly quoted with a ${ }^{14} \mathrm{C}$ date is based on theoretical estimates of the uncertainty from the radioactivity measurements process. Replicate assays of samples, however, provide a realistic measure of precision since the estimate is derived purely from experiment using normal procedures (Otlet 1979; Baxter 1983; Scott, Baxter \& Aitchison 1983).

The preliminary results of the International Collaborative Study show that the highest component of variability occurs in the counting process (Scott et al 1989). The aim of this paper is to discuss the variability in the counting procedure of our laboratory through 1) replicate measurements of background benzene and secondary modern standard, 2) duplicate measurements of benzene synthesized from samples provided by the International Collaborative Study, 3) replicate measurements of the dilution of the ${ }^{14} \mathrm{C}$-labeled benzene standard.

\section{EXPERIMENTAL PROCEDURE AND SAMPLE DESCRIPTIONS}

We used two liquid scintillation counters. Our methodology and age calculation were described previously (Figini et al 1984; Huarte \& Figini 1988). Each sample of $2 \mathrm{ml}$ benzene was weighted $(1.758 \mathrm{~g}$ ) in a vial of $20 \mathrm{ml}$ low-potassium glass (Packard Corp) within which were weighted $0.014 \mathrm{~g}$ of scintillator (t-butyl PBD) using a Sauter 414 balance $( \pm 0.001 \mathrm{~g}$ precision). A single vial was used for all the measurements, alternating background, secondary modern standard and samples for one year of the counting period (4/88-4/89).

The energy window for ${ }^{14} \mathrm{C}$ in a Beckman LS-100 was adjusted placing the lowest limit at the upper end of the ${ }^{3} \mathrm{H}$ curve, and for the Packard 1500 was adjusted between 25 and $156 \mathrm{kev}$. The samples were counted at intervals of $100 \mathrm{~min}$ for a minimum of $2000 \mathrm{~min}$. A $\chi^{2}$ test was applied to detect any unexpected deviation.

We made duplicate measurements with synthesized benzene of samples 9T, 9B, 9U, 9X and 9G of the International Collaborative Study (Stage 3). Each sample was measured in a Packard counter; then the same vial was taken out and measured in a Beckman counter.

We made replicate measurements on aliquots of benzene samples:

B: background benzene Merck art 1783, also used for dilutions.

M: secondary modern standard prepared by dilution of benzene marked ${ }^{14} \mathrm{C}$ supplied by Lab de Metrologie des Rayonnements Ionisants, Gif-Sur-Yvette, with an activity of $1.042 \times 10^{-6}$ $\mathrm{Ci} / \mathrm{g}$, up to an activity equal to the NBS oxalic acid reference standard.

S1: benzene of an activity of ${ }^{14} \mathrm{C}$ equivalent to $5830{ }^{14} \mathrm{C}$ years, prepared by dilution of marked benzene.

S2: aliquots $(0.4 \mathrm{ml})$ of benzene $\mathrm{S} 1$ diluted to $2 \mathrm{ml}$ with background in the same vial. 


\section{RESULTS AND DISCUSSION}

For comparison of the results, we used pooled means calculated without weighting and pooled means calculated with weighting and test procedures of Ward and Wilson (1978).

Tables 1 and 2 show the results of background $B$ and secondary modern standard M samples from two counters. We rejected one result in the measurements of $M$ in the Beckman counter because it was more than three standard deviations ( $\sigma)$ from the mean of the series. The individual count rates of $\mathrm{B}$ and $\mathrm{M}$ were not significantly different and there is a good reproducibility.

TABLE 1

Background B

\begin{tabular}{ccc}
\hline Sample & $\begin{array}{c}\text { Beckman LS-100 } \\
\text { cpm } \pm 1 \sigma\end{array}$ & $\begin{array}{c}\text { Packard } 1500 \\
\text { cpm } \pm 1 \sigma\end{array}$ \\
\hline 1 & $5.165 \pm 0.066$ & $2.794 \pm 0.050$ \\
2 & $5.053 \pm 0.045$ & $2.732 \pm 0.052$ \\
3 & $5.141 \pm 0.068$ & $2.705 \pm 0.050$ \\
4 & $5.107 \pm 0.041$ & $2.714 \pm 0.052$ \\
5 & $5.166 \pm 0.061$ & $2.792 \pm 0.048$ \\
6 & - & $2.747 \pm 0.055$ \\
7 & - & $2.776 \pm 0.043$ \\
8 & - & $2.804 \pm 0.043$ \\
9 & - & $2.853 \pm 0.031$ \\
10 & - & $2.705 \pm 0.030$ \\
11 & & $2.754 \pm 0.033$ \\
\hline Pooled means with & $5.112 \pm 0.024$ & \\
weighting $\pm 1 \sigma$ & & $2.766 \pm 0.012$ \\
Pooled means no & $5.126 \pm 0.021$ & $2.761 \pm 0.014$ \\
weighting $\pm 1 \sigma$ & &
\end{tabular}

The correlation coefficients indicate that these results are independent of the time period in which the measurements were done. The standard deviations of the unweighted and weighted means are approximately equal. The overall means values are determined (plus $\sigma$ ) from subsequent insertion in the age calculation equation.

Table 3 shows the results of the duplicate counts of the International Collaborative Study samples. Sample values in both counters agreed, with the exception of $9 \mathrm{~B}$ and $9 \mathrm{G}$, which were significantly different (Ward \& Wilson 1978). The ${ }^{14} \mathrm{C}$ ages obtained in our lab are not significantly different from the numerical average of all the results for each sample with the exception of $9 \mathrm{G}$ (the results of other laboratories were sent by Marian Scott). We find a positive correlation between the following two variables regarding each test sample: 1) our dates and 2) the difference between our dates and the numerical averages of all laboratories' results. This is evidence for systematic bias in our lab. It is possible that the bias is caused by problems in modern standard count-rate evaluation and it is also probable that it is due to variability among laboratories in the chemical process during preparation for counting. 
TABLE 2

Secondary Modern Standard M

\begin{tabular}{ccc}
\hline Sample & $\begin{array}{c}\text { Beckman LS-100 } \\
\text { cpm } \pm \text { 1 }\end{array}$ & $\begin{array}{c}\text { Packard 1500 } \\
\text { cpm } \pm 1 \sigma\end{array}$ \\
\hline 1 & $14.790 \pm 0.079$ & $14.522 \pm 0.127$ \\
2 & $14.856 \pm 0.143$ & $14.614 \pm 0.128$ \\
3 & $14.796 \pm 0.076$ & $14.409 \pm 0.133$ \\
4 & $14.702 \pm 0.080$ & $14.509 \pm 0.133$ \\
5 & $14.764 \pm 0.098$ & $14.690 \pm 0.128$ \\
6 & $14.552 \pm 0.099$ & $14.677 \pm 0.095$ \\
7 & $14.859 \pm 0.059$ & $14.806 \pm 0.110$ \\
8 & $14.899 \pm 0.094$ & $14.710 \pm 0.110$ \\
9 & $14.870 \pm 0.066$ & $14.676 \pm 0.121$ \\
10 & - & $14.868 \pm 0.082$ \\
11 & - & $14.725 \pm 0.083$ \\
12 & - & $14.808 \pm 0.078$ \\
13 & - & $14.601 \pm 0.077$ \\
14 & - & \\
\hline
\end{tabular}

TABLE 3

Duplicate counts of International Collaborative Study samples

\begin{tabular}{lccrcc}
\hline \multicolumn{1}{c}{ Sample } & Beckman LS-100* & Packard $1500^{*}$ & Mean & $\mathrm{D}^{\dagger *}$ & $\mathrm{~T}^{\ddagger}$ \\
\hline 9T Shell & $600 \pm 80$ & $590 \pm 70$ & $660 \pm 210$ & 0.1 & 0.0 \\
9B Wood 1 & $2480 \pm 70$ & $2290 \pm 50$ & $2228 \pm 115$ & 2.2 & 4.9 \\
9U Wood 2 & $420 \pm 90$ & $360 \pm 60$ & $297 \pm 154$ & 0.5 & 0.3 \\
9X Peat & $3630 \pm 100$ & $3480 \pm 90$ & $3378 \pm 87$ & 1.1 & 1.2 \\
9G Peat & $3530 \pm 60$ & $3780 \pm 70$ & $3388 \pm 120$ & 2.7 & 7.3 \\
\hline
\end{tabular}

* ${ }^{14} \mathrm{C}$ age $\pm 1 \sigma$

** Mean (Ap), numerical average of all results for each sample. Stage 3 International Collaborative Study (Scott, pers commun).

$\dagger \mathrm{D}=\operatorname{diff} /\left(\sigma_{1}^{2}+\sigma_{2}^{2}\right)^{1 / 2}$

$\ddagger \mathrm{T}=\sum_{1}^{\mathrm{n}}\left(\mathrm{Age}_{\mathrm{i}}-\mathrm{Ap}\right)^{2} / \mathrm{\sigma}_{\mathrm{i}}^{2}$

Table 4 shows the results with portions of the same sample, benzene S1, in both counters. There was one rejection in the Beckman counter; it was $>30$ from the mean of the series. Statistical test $\mathrm{T}$ (a $\chi^{2}$ distribution on $\mathrm{n}-1$ degrees of freedom) showed that the numerical value was in all cases close to the appropriate number of degrees of freedom. The overall mean ages obtained in both counters are not to be judged significantly different and they are completely in 
agreement with the expected value $\left(5830{ }^{14} \mathrm{C} \mathrm{yr}\right)$. The standard deviation from unweighted and weighted means are approximately equal. The results suggest good reproducibility in the counting process in our lab during the study period.

TABLE 4

Replicate counts of S1 sample

\begin{tabular}{ccc}
\hline Sample & Beckman LS-100* & Packard $1500^{*}$ \\
\hline 1 & $5780 \pm 100$ & $5930 \pm 90$ \\
2 & $5910 \pm 110$ & $5750 \pm 100$ \\
3 & $5720 \pm 130$ & $5720 \pm 90$ \\
4 & $6120 \pm 130$ & $5780 \pm 100$ \\
5 & $5930 \pm 130$ & $5940 \pm 70$ \\
6 & $6050 \pm 110$ & $5910 \pm 70$ \\
7 & $5800 \pm 110$ & $5800 \pm 80$ \\
8 & - & $5860 \pm 60$ \\
9 & - & $5860 \pm 70$ \\
\hline Pooled means with & & \\
weighting $\pm 1 \sigma$ & $5890 \pm 40$ & $5850 \pm 30$ \\
Pooled means no & & $5840 \pm 30$ \\
weighting $\pm 1 \sigma$ & $5900 \pm 55$ & \\
\hline
\end{tabular}

${ }^{* 14} \mathrm{C}$ age $\pm 1 \sigma$

Table 5 contains a list of ${ }^{14} \mathrm{C}$ ages determined for replicate S2 samples. Two rejections were made in the Packard counter and one in the Beckman counter; all were beyond $3 \sigma$ from the mean of the series. The distribution and range of dates were non-ideal. The overall means value obtained in the Beckman counter of S1 and S2 samples were significantly different. The variability of data of the S2 sample is probably due to the influence of errors in dilution and weighings.

TABLE 5

Replicate counts of S2 sample (dilution of S1)

\begin{tabular}{ccc}
\hline Sample & $\begin{array}{c}\text { Beckman LS-100 } \\
{ }^{14} \mathrm{C} \text { age } \pm 1 \sigma\end{array}$ & $\begin{array}{c}\text { Packard } 1500 \\
{ }^{14} \mathrm{C} \text { age } \pm 1 \sigma\end{array}$ \\
\hline 1 & $6320 \pm 420$ & $6140 \pm 210$ \\
2 & $5690 \pm 480$ & $5840 \pm 220$ \\
3 & $7045 \pm 590$ & $6080 \pm 230$ \\
4 & $5880 \pm 490$ & - \\
\hline 5 & $6780 \pm 500$ & $6020 \pm 130$ \\
\hline $\begin{array}{l}\text { Pooled means with } \\
\text { weighting } \pm 1 \sigma\end{array}$ & $6290 \pm 220$ & $6020 \pm 90$ \\
$\begin{array}{l}\text { Pooled means no } \\
\text { weighting } \pm 1 \sigma\end{array}$ & $6340 \pm 260$ & \\
\hline
\end{tabular}




\section{CONCLUSIONS}

Although the results and their treatment are preliminary, we wish to make the following comments:

1. With the experimental error in the counting process determined in background $\mathrm{B}$, and secondary modern standard $\mathrm{M}$, using the same vial, geometry and benzene purity were not different from those calculated from counting statistics alone.

2. Assuming that the Glasgow average is truth, the results of the samples of the International Collaborative Study (Stage 3) processing in our lab show systematic bias. Our data are generally older than the numerical average of all the results of each sample, which emphasizes the need for more extensive studies and experiments to assess and correct the bias.

3. The experimental error in the counting process determined in replicated measurements of sample S1 was not different from that calculated from counting statistics alone. The differences between replicated measurements of this sample were not significantly different.

4. The differences between replicated measurements of aliquots of sample S2 were significantly different. The variability may be due to errors in the dilution and weighing of each sample.

\section{ACKNOWLEDGMENTS}

This research was supported by the Consejo Nacional de Investigaciones Científicas y Técnicas (CONICET) under PID 3-9194/85. We thank the Comisión de Investigaciones Científicas (CIC.PBA) for the purchase of the Packard 1500 spectrometer. We thank the Centro Parasitológico $y$ de Vectores (CEPAVE) for the use of the Beckman LS-100 spectrometer. We also wish to thank the Facultad de Ciencias Naturales y Museo, Universidad Nacional de La Plata.

\section{REFERENCES}

Baxter, MS 1983 An international tree ring replicate study. In Waterbolk, HT and Mook, WG, eds, ${ }^{14} \mathrm{C}$ and archaeology, Proc. PACT 8: 123-132.

Figini, A, Gómez, G, Carbonari, J, Huarte, R and Zubiaga, A 1984 Museo de La Plata radiocarbon measurements I. Radiocarbon 26(1): 127-134.

Huarte, RA and Figini, AJ 1988 La Plata Radiocarbon Laboratory liquid scintillation counting and inter-laboratory check samples. Radiocarbon 30(3): 347-350.

Otlet, RL 1979 An assessment of laboratory errors in liquid scintillation methods of ${ }^{14} \mathrm{C}$ dating. In Berger, R and Suess, HE, eds, Radiocarbon dating, Internatl ${ }^{14} \mathrm{C}$ conf, 9th, Proc. Berkeley/Los Angeles, Univ California Press: 256-267.

Scott, EM, Aitchison, TC, Harkness, DD, Baxter, MS and Cook, GT 1989 An interim progress report on Stages 1 and 2 of the International Collaborative Program. In Long, A and Kra, RS, eds, Internatl ${ }^{14} \mathrm{C}$ conf, 13th, Proc. Radiocarbon 31(3): 414-421.

Scott, EM, Baxter, MS and Aitchison, TC $1983{ }^{14} \mathrm{C}$ dating reproducibility: evidence from a combined experimental and statistical programme. In Waterbolk, HT and Mook, WG, eds, ${ }^{14} \mathrm{C}$ and archaeology, Proc. PACT 8: 133-145.

Ward, GK and Wilson, SR 1978 Procedures for comparing and combining radiocarbon age determinations: a critique. Archaeometry 20: 19-31.

Editor's note: This paper was not actually presented at the Workshop but was considered appropriate for inclusion in these Proceedings. 